\title{
Evaluation of Reduction of Swelling and Trismus after Molar Tooth Surgery due to Dexamethasone Injection in the Dental Clinic in Moscow, Russia, Dental Department(Clinical Study)
}

\author{
Hamed Nabahat ${ }^{1 *}$, Faezeh AzaditalabDavoudabadi², Melika Tahan ${ }^{3}$, Sahar Asakereh $^{3}$, Zahra Boroumand $^{3}$, \\ Mahnaz Esmaeilnezhad ${ }^{4}$, Mahsa Esmaeilnezhad ${ }^{4}$
}

1 Yevdokimov Moscow State University of Medicine and Dentistry, Moscow, Russian Federation, Russia

2Sechenov First Moscow State Medical University, Moscow, Russian Federation, Russia

3Evdokimov Moscow State University of Medicine and Dentistry (MSMSU ), Moscow, Russian Federation, Russia

4Pirogov Russian National Research Medical University, Moscow, Russian Federation, Russia

Submission: June 25, 2021; Published: July 06, 2021

*Corresponding author: Hamed Nabahat, Yevdokimov Moscow State University of Medicine and Dentistry, Moscow, Russian Federation, Russia

\section{Abstract}

The extraction of the impacted mandibular third molar is a common oral surgical procedure; and it is often attended by complications, which are distressing to patients. Pain, trismus, and swelling are common complications reported, and they are thought to arise from inflammatory response which is a direct and immediate consequence of the surgical procedure. Medications such as corticosteroids have been used to reduce swelling and postoperative complications. Due to the important subject and importance of preventing complications of dental treatments in this study, investigating the effect of dexamethasone injection before surgery lower incisors were used to reduce swelling and postoperative trismus. A randomized double-blind experimental study using a randomized clinical trial. The observation technique was performed for 22 months. 40 patients ( 20 females and 20 males) referred to the Dental clinic for extraction of the lower third molars were randomly divided into case and control groups. This research was conducted as a case study for two years on several people in Russia. In the case group, before surgery Dexamethasone was injected and in the case group, distilled water was used as a placebo. The size of the distance between the two mandibular angles and the amount of opening oral occlusion was measured and recorded in millimeters before surgery, 48 hours, and one week after surgery. Due to the nature of the variable, the t-test was used to examine the differences. As a result, the use of injectable dexamethasone before surgery to extract the third molar reduces swelling and Trismus after is operated.

Keywords: Third molar; Swelling; Trismus; Dexamethasone injection; Case study; Tooth surgery

\section{Introduction}

Impacted teeth are a type of anatomical problem in which a tooth fails to erupt within the physiologically predicted time frame. Third molars are the most often impacted teeth, with over $77 \%$ of people having them, and extraction is the most common oral surgical treatment. In fact, $33 \%$ of the population has at least one impacted third molar, which frequently leads to food retention, caries, pain, edema, and second molar root resorption and, consequently, its surgical extraction [1]. Despite the frequent surgical removal of third molars, the occurrence of accompanying postoperative morbidities is relatively common. The invasive manipulation of soft and hard tissues during tooth extraction involves different factors that can influence the patient's postoperative course in terms of pain, swelling, trismus, and healing. In this context, the selection of the surgical access flap can affect the post-operative outcomes following third molar surgery, including many complications [2]. Trismus or jaw lock is a painful condition due to spasm of the jaw muscles in which the mouth does not open completely.

In addition to causing pain that may even be felt in the ears, face, neck, and shoulders, trismus can lead to problems eating, talking, and oral hygiene. Clicks are often heard when a person tries to open their mouth. Trismus occurs when a person is unable to open their mouth more than $35 \mathrm{~mm}$. It can be caused by damage to the jaw, oral surgery, infection, cancer, or radiation therapy for head and throat cancers. Most cases of trismus are temporary, and usually, last less than 2 weeks, but some may be permanent. Inflammation, the body's natural defense mechanism to injury or cell death. This response is accompanied by redness, heat, pain, 
and swelling in the area is determined. When tissue damage occurs, the amount high levels of histamine, bradykinin, serotonin, and chemicals are released in the area. These substances are especially histamine cause local vasodilation in the area and increase blood flow to the affected area, as well as permeability (permeability of capillaries and venules). Methods of oral surgery and removal of third molar teeth the latent are often associated with many problems and discomforts in the afterlife. They are accompanied by surgery for patients. Reduce problems after surgery is the goal of all maxillofacial surgeons Much to alleviate the complications of occult wisdom tooth surgery been tested. One of these methods is the use of effective local anesthetics long-term glucocorticosteroids and anti-inflammatory drugs are non-steroidal [3]. Of course, good surgery and gentle tissue manipulation and prevention, from unintentional trauma to the tissue, some pain and minimizes discomfort even though it cannot remove completely. Use of corticosteroids before surgery to reduce pain, edema, and Trismus helps after dental surgeries.

Proponents of her case have been working to make the actual transcript of this statement available online Postoperative complications are effective [4]. On the other hand, opponents of using this information on the side effects and widespread side effects of corticosteroids are concerned. Various studies have shown swelling, trismus, and back pain reduces the action of all using systemic steroids have found that among them can be [5-9]. In another study by Azher et al. order to compare the antibiotic effect of amoxicillin / clavulanic (Acid and placebo in the prevention of complications after molar extraction [10]. The third lies in 490 people (259 people antibiotics and 231 people) Placebo (reported that in $9.1 \%$ of group members Antibiotics and $9.12 \%$ of people in the placebo group have side effects after Tooth extraction has been observed to be statistically significant $[3,11]$. to evaluate the effect of metronidazole $1600 \mathrm{mg}$ and placebo as a single dose before surgery, a study on 119 patients who had dental implants the third half-hidden molar was referred to the design and formation dry socket in 10 of 59 patients taking metronidazole 13 patients also received Placebo reported [12]. In this study, two variables of pericronitis and use of oral contraceptive pills with dry form socket had a significant relationship. Due to the importance of the issue of complication prevention in treatments dentistry and the existence of disagreement among researchers in the use of the aim of this study was to evaluate the effect of dexamethasone injection before maxillofacial wisdom tooth surgery to reduce swelling and Trismus was performed postoperatively.

\section{Materials and Methods}

Research by randomized double-blind clinical trial (using randomized double - blind clinical trial) with observation technique was performed. 40 people including 20 men and 20 women between the ages of 18 and 35 who have no systemic. They had no problems and were not taking any medication, either no use for prescribing corticosteroids. They were not selected and randomly selected once as a group and one as controls. All teeth they are mesioangular and their latency in hard tissue is approximately was similar. In the case group from dexamethasone sodium phosphate to injectable form immediately before the operation and in the control group of water $2 \mathrm{ml}$ distillate containing $8 \mathrm{mg}$ was used as a placebo. For each patient is given one placebo session and one session after dexamethasone random and hidden form is injected from the patient and the researcher. Perform IV injection without informing the injector and the patient was a kind of medicine. None of the patients before the onset of pain, swelling, there were no redness or signs of gum disease in the area of operation.

Maximum amount of mouth opening before surgery in all patient was examined. All patients open their mouths directly so that they do not have jaw deviation, pain and discomfort. Maximum amount of mouth opening by measuring the distance between the edges of the incisal central and upper central teeth by fracture and obtained in millimeters. The amount of inflation was also changed according to the caliper Millimeters were measured. Thus, the angle between the two sides the mandible before surgery from the angle of the two sides of the mandible after the operation was reduced and thus the amount of swelling was obtained. All surgeries performed by assistants in the field of oral and maxillofacial surgery Face in the surgery department of Moscow Dental School, Med Amulet clinic (Russian federation). Most surgeries take 30 to 60 minutes and the type of incision was similar in all operations and was of the horizontal and liberating type. After Anesthesia, Mandibular nerve trunk block, lingual nerve and long buccal nerve, incision and flexion of the flap surgery, some of the bone covering the teeth is removed after sectioning the tooth and removing it, the area is rinsed and sutured. In all patient's antibiotic (amoxicillin) Cillin 500 mg every 8 hours and painkillers (nurofen $400 \mathrm{mg}$, every 6 hours) after surgery orally was consumed. For statistical analysis due to the quantitative nature of the variables the t-test was used.

\section{Findings}

In Table 1, the rate of mouth opening before surgery was checked after 48 hours and a week after surgery in patients with use of placebo as well as dexamethasone given. According to this table, the rate of mouth opening in the case group is 35.4 \pm 3.32 (standard deviation \pm average) $\mathrm{mm}$ before operation, to $18.5 \pm 2.72 \mathrm{~mm}$ in 48 postoperative hours, also $35.4 \pm 3.32 \mathrm{~mm}$ was the week after the operation. This amount is controlled in the group $27.38 \pm 2.78$ and $18 \pm 5 / 35.4 \pm 3.32 \mathrm{~mm}$ respectively. Based on t-test, the difference between the two groups after 48 hours and a week later was significant $(\mathrm{P}<0.0001)$ shown in (Figure 1). In the case group, the rate of inflation of $10.22 \pm 2.59 \mathrm{~mm}$ in 48 hours after surgery to $4.05 \pm 3.14 \mathrm{~mm}$ was reached one week after surgery. In the group control also this amount from $19.17 \pm 4.48$ in 48 hours after the operation reached $10.22 \pm 3.54 \mathrm{~mm}$ in one week after the operation (Table2), (Figure $1 \& 2$ ). 


\section{Advances in Dentistry \& Oral Health}

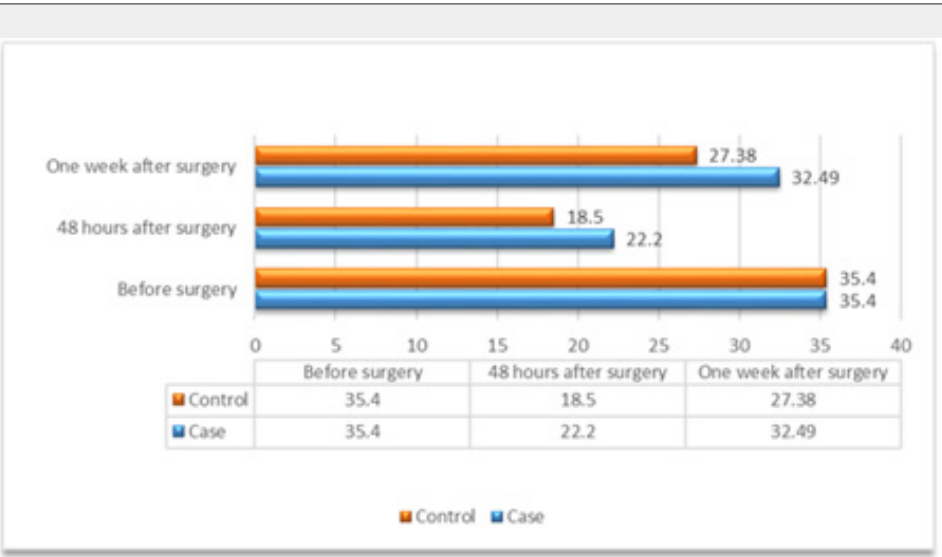

Figure 1: The amount of mouth opening in two groups at different times ( $\mathrm{mm}$ ).

Figure 2: Swelling in groups in 48 hours and one week after surgery $(\mathrm{mm})$.

Table 1: Mouth opening before surgery, 48 hours and one week after surgery in patients and controls (mm).

\begin{tabular}{|c|c|c|c|}
\hline & Before surgery & $\mathbf{4 8}$ hours after surgery & One week after surgery \\
\hline Case & $35.4 \pm 3.32$ & $25.1 \pm 2.98$ & $31.53 \pm 3.85$ \\
\hline control & $35.4 \pm 3.32$ & $21.8 \pm 2.72$ & $27.38 \pm 2.78$ \\
\hline Result of T-test & $\mathrm{P}=1$ & $\mathrm{P}=0 / 0001$ & $\mathrm{P}=0 / 0001$ \\
\hline
\end{tabular}

Table 2: Swelling 48 hours and one week after surgery in case and control patients ( $\mathrm{mm}$ ).

\begin{tabular}{|c|c|c|}
\hline & 48 hours after surgery & One week after surgery \\
\hline Case & $10.22 \pm 2.59$ & $4.05 \pm 3.14$ \\
\hline control & $19.17 \pm 4.48$ & $10.22 \pm 3.54$ \\
\hline Result of T-test & $\mathrm{P}=0 / 0001$ & $\mathrm{P}=0 / 0001$ \\
\hline
\end{tabular}

\section{Results}

The study showed a statistically significant difference between the two groups of use injectable dexamethasone case and distilled water control (before third molar surgery lies in the amount of swelling and opening of the mouth $(\mathrm{P}<0.0001)$. In the research of Bexendale et al. was concluded that use of oral dexamethasone prophylactically in reducing the need for analgesics in patients 
is beneficial as a result [5]. His research is consistent with the present study in another study by Ammar et al. [13]. Restriction on opening the mouth after consumption Dexamethasone at 17. $7 \%$, as well as pain by Dexamethasone was reduced by $50 \%$. In his study the need for analgesics after surgery is $37 \%$ after Dexamethasone administration decreased in $76 \%$ of patients. They preferred to prescribe dexamethasone before surgery.

The results of this study in terms of reducing the limitation in the rate of opening the mouth is consistent with the results of the present study but in the case of others. The results presented in his study as the possibility of examining them in the present study did not exist, so no comparisons can be made between the two research. In a study by Phadnaik et al. evaluation of the effect of intramuscular dexamethasone on subsequent neurapraxia Trisomy and discomfort were performed from the incised third molars most patients were affected by steroids [7,14]. However, this is the difference between the control group and the receiving group Dexamethasone was not statistically significant. In his study, none there was no difference in swelling and daily pain between the two groups.

\section{Discussion}

This study contradicts the results of the present study which can be related to the dose of the drug and the number of injections to a clinical trial by Mubarak et al. [15]. The aim of comparing the effect of rofecoxib and dexamethasone in reducing Trismus was performed after the extraction of the third molar tooth concluded that intraoperative use dexamethasone is an effective limiting treatment process Trismus is after surgery [16,17]. In their research as well the combination of Dexamethasone and rofecoxib is more effective than the previous method in decreased trismus and postoperative pain have been reported. The overall results of this study showed that Dexamethasone was effective in reduction of complications after latent third molar surgery with research results the present is consistent but in terms of different variables in two studies have been reviewed and the results are not comparable. Despite the positive effects of corticosteroids, their use with various problems and complications, including: It can be used to inhibit the hypothalamic-pituitary-adrenal axis, development of Cushing's syndrome, Cataract, Glaucoma, Increased pressure Blood, muscle analysis and weakness, osteoporosis, mood swings and mood and psychosis, thin and brittle skin, delayed repair Wounds, decreased resistance to infection, ulcer activation peptic and diabetes noted. Other important forms that use the downside of these drugs is that they can be taken the symptoms of the underlying disease are hidden. Ways to a minimum delivering these side effects include topical application of the drug, treatment on a daily basis and reduce the dose shortly after Get the answer. Decreased hypothalamic axis activity - Pituitary-adrenal glands are usually treated with glucocorticoids for a long time, either in large pharmacological amounts or in combination. There are two ways to do this that need to be avoided consider all precautions and prohibitions. Despite these side effects, corticosteroids in the face Proper use of valuable drugs in the treatment of inflammation they are.

\section{Conclusion}

In general, Oral dexamethasone reduces pain and swelling following oral surgical procedures. Dexamethasone reduces the opening restriction oral and post-operative swelling reduction is more effective than placebo.

\section{References}

1. Alcântara CEP, Falci SGM, Oliveira-Ferreira F, Santos CRR, Pinheiro MLP (2014) Pre-emptive effect of dexamethasone and methylprednisolone on pain, swelling, and trismus after third molar surgery: a split-mouth randomized triple-blind clinical trial. Int J Oral Maxillofac Surg 43(1): 93-98.

2. Arteagoitia I, Diez A, Barbier L, Santamaría G, Santamaría J (2005) Efficacy of amoxicillin/clavulanic acid in preventing infectious and inflammatory complications following impacted mandibular third molar extraction. Oral Surg Oral Med Oral Pathol Oral Radiol Endod 100(1): e11-e18.

3. István K, Kinga K, Kata C, Ferenc H, Hossein AA, et al. (2021) Delayedonset infections after lower third molar surgery: a Hungarian casecontrol study. Oral Surgery, Oral Medicine, Oral Pathology and Oral Radiology.

4. Iwanaga J, Kunisada Y, Masui M, Obata K, Takeshita Y, et al. (2021) Comprehensive review of lower third molar management: A guide for improved informed consent. Clinical Anatomy 34(2): 224-243.

5. Warraich R, Faisal M, Rana M, Shaheen A, Gellrich NC, et al. (2013) Evaluation of postoperative discomfort following third molar surgery using submucosal dexamethasone-a randomized observer blind prospective study. Oral Surg Oral Med Oral Pathol Oral Radiol 116(1): 16-22.

6. Baxendale BR, Vater M, Lavery KM (1993) Dexamethasone reduces pain and swelling following extraction of third molar teeth. Anaesthesia 48(11): 961-964.

7. Azher S, Patel MA (2021) Antibiotics in Dentoalveolar Surgery, A closer look at Infection, Alveolar Osteitis and Adverse Drug Reaction. J Oral and Maxillofac Surg S0278-2391(21)00405-5.

8. Agrawal P, Agrawal K, Shakapuram G (2021) A Comparative Study to Evaluate the Effects of Dexamethasone \& Tube Drain on Post-Operative Sequelae After Surgical Extraction of Impacted Mandibular Third Molars-An In Vivo Study. European Journal of Molecular \& Clinical Medicine 7(11): 8827-8839.

9. Rezvi FB, Kathiravan DG (2021) Antibiotics Vs Mouthwash, which is the Better Controller of Post Extraction Infections. Annals of the Romanian Society for Cell Biology pp. 2488-2496.

10. Naserzadeh Y, Mahmoudi N, Pakina E, Marie Wase IA, Heydari M, et al. (2019) Parameters Affecting the Biosynthesis of Gold Nanoparticles Using the Aquatic Extract of Scrophularia striata and their Antibacterial Properties. Journal of Nanoanalysis 6(2): 105-114.

11. Thomas S, Beevi S (2007) Dexamethasone reduces the severity of postoperative sore throat. Can J anesth 54(11): 897-901.

12. Ammar AS, Mahmoud KM (2012) Effect of adding dexamethasone to bupivacaine on transversus abdominis plane block for abdominal hysterectomy: A prospective randomized controlled trial. Saudi journal of anaesthesia 6(3): 229. 
13. Phadnaik M (2015) National symposium on periodontal diseases in pediatric patients organized. Journal of Indian Society of Periodontology 19(4): 477.

14. Naserzadeh Y, Kartoolinejad D, Mahmoudi N, Zargar M, Pakina ELENA, et al. (2018) Nine strains of Pseudomonas fluorescens and P. putida: Effects on growth indices, seed and yield production of Carthamus tinctorius L. Research on Crops 19(4): 622-632.

15. Mubarak HA, Al-Adily SS (2021) A Randomized Case-controlled Clinical Trial of the Effect of Preemptive Etoricoxib, Prednisolone and a Control Group on of Postoperative Sequelae after Surgical Removal of Impacted Mandibular Third Molars. Medico Legal Update 21(2): 563-571.

16. Tirupathi S, Rajasekhar S, Maloth SS, Arya A, Tummalakomma P, et al. (2021) Pre-emptive analgesic efficacy of injected ketorolac in comparison to other agents for third molar surgical removal: a systematic review. J Dent Anesth Pain Med 21(1): 1.

17. Younis M (2020) Evaluation of Effects of Pre-Emptive Sub-Mucosal Injection of Dexamethasone versus Methylprednisolone on PostOperative Sequelae Following Third Molar Surgery-A Comparative Clinical Study. Annals of International Medical and Dental Research 6(5): 14 .

Your next submission with Juniper Publishers will reach you the below assets

- Quality Editorial service

- Swift Peer Review

- Reprints availability

- E-prints Service

- Manuscript Podcast for convenient understanding

- Global attainment for your research

- Manuscript accessibility in different formats

( Pdf, E-pub, Full Text, Audio)

- Unceasing customer service

Track the below URL for one-step submission https://juniperpublishers.com/online-submission.php 